Article

\title{
Consumer Behaviour of Purchasing Biofortified Food Products
}

\author{
Giuseppe Timpanaro, Claudio Bellia *D, Vera Teresa Foti and Alessandro Scuderi \\ Department of Agricultural Food and Environment (Di3A), University of Catania, Via Santa Sofia 98, \\ 95126 Catania, Italy; timpanar@unict.it (G.T.); v.foti@unict.it (V.T.F.); scuderia@unict.it (A.S.) \\ * Correspondence: c.bellia@unict.it; Tel.: +39-095-7580336
}

Received: 14 July 2020; Accepted: 28 July 2020; Published: 5 August 2020

\begin{abstract}
In light of increasing attention on biofortified products from the institutional, scientific and industrial worlds, we investigate consumer knowledge, consumer choice, the relationship between consumer choice and lifestyles, willingness to pay, and factors influencing consumer groups regarding biofortified foods. Complicating the matter is the lack of a clear definition of biofortified foods in the last proposal of the Codex Alimentarius Commission dated 26 November 2018. Research has shown the importance of market information and variables related to lifestyle, socio-demographic characteristics, knowledge of nutritional principles, and diet, to understanding consumers' purchase and consumption choices regarding biofortified products. Our research shows that at present the potential consumer of biofortified food products is generally confused and uninformed, conditions that, even when there is a high willingness to pay, limit purchases of biofortified products. Even in the absence of a concise definition and clear labelling at a globally recognized level, in Italy biofortified products are increasingly widespread (products biofortified with selenium, iodine, etc.), confirming consumer demand for this category of product.
\end{abstract}

Keywords: functional food; health; tomato; claims; GMOs

\section{Introduction}

In recent years, consumer choice has been influenced by increasing attention on the food-health relationship [1-5]. The increased sensitivity of people towards their own well-being and health has thus favoured the development by the agri-food system of products with healthy connotations [6,7].

This trend is confirmed by recent studies that identify "healthiness" as one of the main reasons for determining food choices in the countries of the European Union $[4,8,9]$.

The food-health connections are therefore increasingly becoming the focus of attention of the modern consumer [10-12], reducing the role of food as a source for the body's nutritional needs and enhancing its role as a tool for the prevention and treatment of diseases [6].

In this context, "functional foods" are an important tool available to the consumer as a way of combining food and health objectives [13]. Functional foods are a sector in continuous development both in developed countries and in poor countries at risk of hunger, albeit with different approaches. In developed countries, functional foods represent a form of product differentiation and a healthy contribution to the diet, while in poor countries, where biofortified food crops are more developed, they serve to compensate for deficiencies in microelements, a strategy to reduce malnutrition in many areas of the world [14]. In this context, types of functional food are categorized as fortified products, enriched products, altered products and enhanced commodities [7].

Nutritional knowledge has a strong influence on the fight against malnutrition and disease [15]. Biofortification is considered in several countries as a strategy to reduce micronutrient deficiency through natural processes, agronomic practices, traditional plant breeding and GMOs $[2,3,16,17]$. 
There is increasing attention on biofortified products from the institutional, scientific and industrial worlds. We investigate consumer knowledge, consumer choice, the relationship between consumer choice and lifestyles, willingness to pay, and factors influencing consumer groups regarding biofortified foods [18-21].

\section{Material}

\subsection{Definition of Functional and Biofortified Foods}

Functional food has been introduced in Japan and has been broken down into to four main dimensions $[9,12,13]$ : the characteristics of the food, the health benefits, the level of functional attributes present and the attitude toward consumption. In Japan, with an ageing population due to increased life expectancy, the health of the population is increasingly affecting the national health expenditure [5]. The Japanese government decided to invest in research aimed at the development of foods to improve the quality of life. This led to the creation of the FOSHU (Foods for Specified Health Use) commonly known in Japan as Tokutei Hokenyo Shokuhin, whose legal definition dates back to 1991 [7].

These foods form a distinct group within the national regulatory framework and belong to the class called 'Food with Health Claims', which is in turn divided into two subclasses. The first, called FNFC (Foods With Nutrient Function Claims), i.e., foods that display the nutritional functions of the ingredients (vitamins and minerals) on the label, and the second, called FOSHU (Foods for Specified Health Use), which includes foods with officially approved claims of physiological effects on the human body [7].

FOSHU are also the subject of a further regulatory subset, as they also belong to FOSDU (Food for Special Dietary Uses), a class of foods that could be considered the equivalent of Italy's "Dietetic Foods" [12].

According the Japanese sample, it is now accepted that a functional food is a common "novel" product so that it can provide consumers with benefits in addition to nutrition.

Although there is as yet no universally recognised definition of the term "functional food", there is general agreement with the one published in the "Scientific Concepts of Functional Foods in Europe, Consensus Document" [4], where functional foods are defined as follows: "a food can be considered functional if it satisfactorily demonstrates that it has positive and targeted effects on one or more specific functions of the body that go beyond normal nutritional effects, so that it is relevant to improving health and well-being and/or reducing the risk of disease. It is understood that functional foods must continue to be foods and must demonstrate their action in the amounts in which they are normally consumed in the diet. Functional foods are neither tablets nor capsules, but foods that form part of a normal diet".

There are also a number of relevant rules in the field of functional food, depending on the type of functionality or the origin of the functional ingredient. These include Regulation (EC) 1925/2006 on the addition of vitamins, minerals and certain other substances with beneficial properties.

Therefore, from a practical point of view, a functional food can be $[4,13]$ :

- a natural food in which one of its components has been improved through enhanced growing conditions;

- a food enriched with some component to produce a benefit;

- a food from which one or more components have been eliminated to subtract or diminish the adverse effects on health;

- a food in which one or more of its constituents has been chemically modified to improve the health status of the consumer;

- a food in which the bioavailability of one or more of its components has been increased in order to improve the uptake of a beneficial component;

- any combination of the above. 
In the light of the above, the definition of functional foods [22] has been developed, which distinguishes it from other categories:

- Fortified Food: it is a food which, through a technological process such as fortification, is made more nutritious without altering its energy value. Mineral salts or vitamins are added to a food in order to make it more nutritious.

- Enriched Food: foods in which the percentage of one or more nutrients naturally present in the food is increased.

- Supplementary Food: a subcategory of fortified foods, the only difference being that a nutrient is added that is not naturally present in the food (such as fatty acid $\omega-3$ or phytosterols in milk and its derivatives, carotenoids and vitamin $\mathrm{D}$ to margarine, etc.).

Biofortified products, being a subset of functional foods, do not have their own regulation, a shortcoming that generates confusion among consumers [23].

The problem of defining biofortified products stems from a definition proposed by the Codex Alimentarius Commission on 26 November 2018. The definition under review has been deemed unacceptable: "Biofortification is any process other than conventional addition to food whereby nutrient content is increased or becomes more bioavailable in all potential food sources for the intended nutritional purposes" [24]. The key question here is whether the above definition of biofortification should be broad enough to include genetically modified organisms (GMOs) (recombinant-DNA technology) "Biofortification is the process whereby any nutrients or related substances of all potential source organisms or foods are increased by a measurable level [and/or] become more bioavailable prior to processing for the purpose of improving nutritional quality of food for improved human health" [25-28]. Biofortification is simply the process by which the nutritional quality of food crops is improved through plant breeding with the aim of making the nutrients bioavailable after digestion [17]. To most consumers, that means "conventional" plant breeding [26,29].

Figure 1 shows the regions with the highest micronutrient deficiency, as highlighted by the World Health Organization (WHO) [30]. A proposed definition of a biofortified product at a regulatory level is the so-called novel foods and, therefore, functional foods, whose principles and requirements are identified in EU Regulations 178/2002 and 2283/2015 and in the European Food Safety Authority (EFSA).

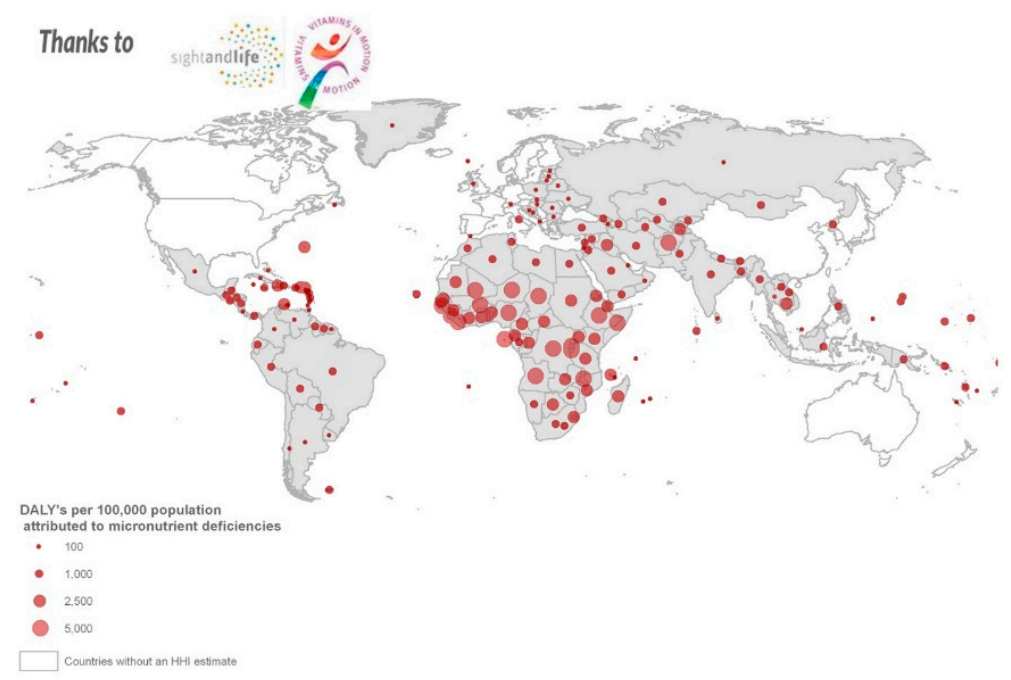

Figure 1. The Word maps of micronutrient deficiency (WHO, 2020).

The Codex Alimentarius Commission first began to discuss biofortified foods in 2005, thanks to a document submitted by Canada to the Codex Committee on Nutrition and Foods for Special Dietary Uses (CCNFSDU) on the possible applicability of biofortified foods as essential nutrients. This document highlighted the growing area of food fortification and how it had led to positive results for public health. 
The European Union has thus drafted a document to discuss biofortification in the absence of a proper definition. The introduction of the document proposes biofortification for the optimization, improvement, and the fortification of nutrients, but fails to define the acceptable methods of production. Without defining these techniques, the European Union in fact obfuscates the difference between the different biofortification techniques: (1) genetic engineering (assuming genetic manipulation of nucleotide sequences by silencing and/or over-expressing phenotypic characters); (2) classical breeding techniques (carried out through cross-pollination) used to obtain species with improved nutritional characteristics; (3) agronomic techniques, including soil or foliar fertilization, above-ground cultivation systems and herbaceous grafting, some samples are shown in Figure 2.
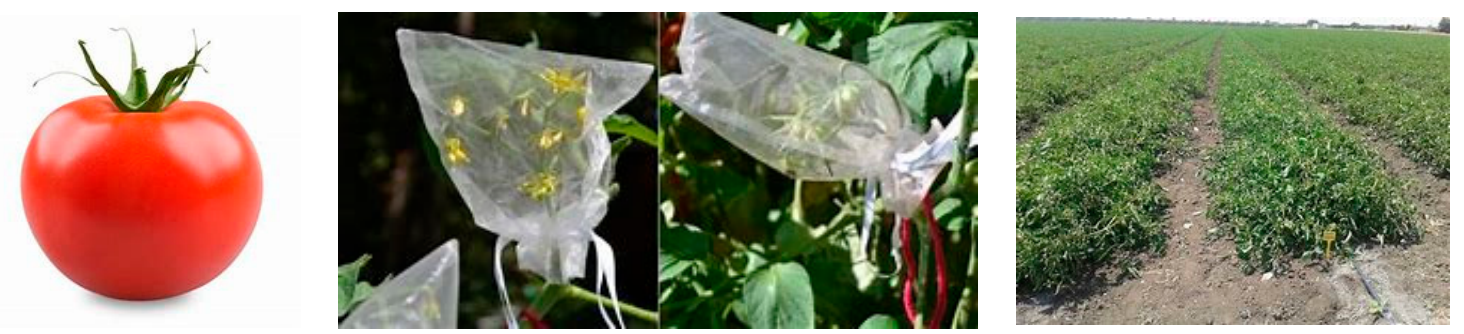

Figure 2. The different biofortification techniques: Genetic engineering, Techniques of classical genetics selection and agronomic techniques (experimental fields).

The EU believes that "bioavailability of nutrients" should be improved, which means "the amount of ingested nutrient that is absorbed and available for physiological functions and that depends on digestion, dietary matrix, absorption of intestinal cells and transport to cells". Several in-depth studies have been conducted to identify and measure the bioavailability, effectiveness and efficiency of biofortification of basic crops [11,31].

The EU discussion paper also mentions that consumers may have difficulties distinguishing a biofortified food from a fortified product, for example, in the case of an organic food that has been biofortified using modern technology or fertilisation. These are the reasons why, before discussing the criteria for the use of the terms biofortification and biofortified foods, the EU would like to clarify the term "biofortification" in food labelling. In the meantime, it is considered acceptable to apply existing Codex texts that can be adapted to biofortified foods without correction.

\subsection{Consumer Trends of Biofortified Products}

The food consumption behaviours related to health products have been the subject of numerous studies in recent years $[9,18,32-34]$, which have shown that the simple need to satisfy the nutritional needs of individuals has progressively decreased. In an attempt to grasp the motivations that animate a process that is both homologation and diversification and to bring out the distinctive traits that characterize purchasing choices, a multidisciplinary approach has become necessary, which has led to an extension of the field of investigation to psychology and anthropology, together with the classical spheres of economics and sociology.

Recently, analytical developments have made it possible to adapt the neoclassical approach, based on maximising the utility function under the budgetary constraint, on the assumption that the consumer is fully informed. An initial review of this approach to consumption [32] shows that consumer preferences are not dictated by a single ordinary utility function but by a family of them and that tastes and preferences, sometimes influenced by extrinsic factors (fashion, advertising, etc.), contribute to changing the process of choice. In the following phases, it has been seen that the process of choice is based not so much on the comparison between products, but on the comparison between their characteristics and their possible combinations $[10,19,35]$.

In this way, in purchasing decisions, the concept of goods is replaced by that of characteristics and the consumer activity becomes an activity in which the propaedeutic knowledge is produced by 
the interaction of two elements: ability and time $[9,18,36]$. As a result of this interaction, consumer choice becomes increasingly complex and articulated, leading to a shift from standardised to highly differentiated goods, with an increasing service content.

In the psychological area, some models analysing consumer behaviour have established themselves around the "stimulus-response" principle [13]. This principle disregards the personal characteristics of the subject determining the conscious attitude, but rather concerns the way in which the dynamic evolution of the learning process impacts on the individual. In modern times and through the study of behavioural psychology, it has been understood that, based on knowledge of the mechanisms of learning and memorization, it is possible to condition the consumer's attitude towards certain products [34].

In sociological terms, the role of cultural and social structures in determining purchasing and consumption behaviour is emphasized, once again questioning the role of exogenously given preferences [11]. Social conditioning has found ample space in institutionalist theory [9] and in particular the so-called trickle-up process, a concept based on the tendency to emulate the behaviour of the higher social classes. In societies that have reached the so-called satiety point $[5,16,37]$, emulatory and inspirational mechanisms determine both an increase in the consumption of higher-quality products and the progressive abandonment of low-cost goods, up to a positive correlation between the price level and the quantities consumed. The centrality of social phenomenology in the explanation of consumption behaviour had already been widely supported, which states that consumption is a social phenomenon with a generally demonstrative character. The satisfaction that an individual can derive from his or her consumption depends largely on a comparison between his or her own standard of living and that of the groups with which he or she establishes social relations. Consumer behaviour is based on interdependent preferences and is influenced by that of the other individuals with whom he or she comes into contact. The most significant consequence of this interdependence is the so-called "demonstration effect". Finally, a further strand of research is the "theory of signs" [12], according to which the individual continuously searches for differentiation on the social level through the consumption of goods capable of communicating distinctive values. The consumption process is considered a set of signs, whose meanings depend on the evolution of the socio-cultural context.

In this framework, the evolution of the consumer together with the growth in the number of foods bearing functional claims placed on the market in recent years, and the confusion over definitions, raise the issue of clarity of information accessible to the consumer.

The functional food market is characterized by the presence of information asymmetry between consumers and producers, especially with regard to some fundamental aspects, such as the credibility and effectiveness of the various claims. Several works have concluded that information and communication activities are essential to reduce this phenomenon [7]. Market failure increases consumers' uncertainty about the real nature of product attributes [38], negatively affecting the consistency between the consumer choice and consumer preference system.

Moreover, according to Akerlof, an effect linked to the asymmetric distribution of information between producers and consumers is that, in the short to medium term, higher quality products can be "driven out" of the market by lower quality goods. In fact, when producers fail to effectively convey information representative of the functional attributes of food, a homologating effect can be generated to the detriment of the recognition of a premium-price for higher-quality products.

In conceptual terms, in order to understand the importance of information associated with purchasing processes, consumer goods can be classified into three main types $[5,11,14,31,39]$ :

(1) Search goods: are those goods whose characteristics can be determined and evaluated before the purchase, for example, shoes: you identify the model, choose the colour and the size, you try them on and finally you buy.

(2) Experience goods: these are those goods whose characteristics, such as taste, quality and freshness, are difficult to determine in advance and can only be "verified" after the purchase and consumption process. However, in this case, while consumers can identify and classify the real quality 
of a product only after its consumption, some elements, such as the reputation of the seller, a quality and certification system, as well as a brand with a good positioning, represent important signals of quality and a guarantee for buyers, which are beforehand evaluated.

(3) Finally, there are credence goods, i.e., those products whose quality and safety cannot be adequately verified and evaluated even after the purchase and consumption process [40-42]. With these types of products, consumers are therefore subject to high levels of uncertainty, which cannot be reduced because there is no perfect information. Examples could be the health characteristics of particular food products, including functional products and biofortified products.

Biofortified products fall into the last category, as some of their characteristics cannot be verified even after the purchase and consumption process. In this context, information on the quality of biofortified products can be understood as a public good [29], with characteristics of non-rivalry and non-exclusivity; there are no substitutes for the information itself and, if made available to a consumer, it is usually available to all others. One of the possible effects of this problem is to provide producers with incentives to amplify the scope of the benefits associated with the product by misleading the consumer. Consumers with limited, imperfect or contradictory information may not be able to make choices consistent with their preferences. This may happen more easily when the health effects of a food are verifiable in the medium to long term [9].

The system governing the regulation of health claims is being refined, and progress is being made to help to reduce the information asymmetry between producers and consumers. To provide support and assurance to the consumer, EFSA has defined the process of assessing health claims stated on the label, through EC Reg. 1924/2006 and EU Reg. EU 1047/2012.

\section{Methods}

The analysis has two distinct objectives: the identification of emerging consumption profiles through an exploratory analysis and the definition of the main characteristics that influence the willingness to pay for biofortified products [27,43], through the use of an econometric model. The analysis focuses on tomatoes with a high lycopene content, like show Figure 3.
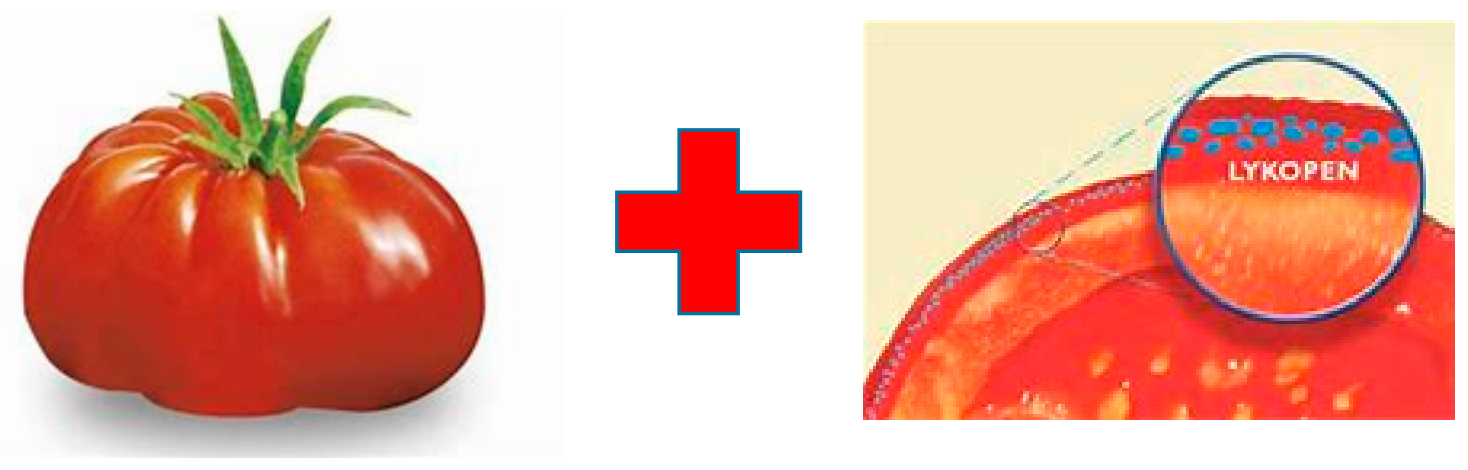

Figure 3. Tomato biofortified by the addition of Lycopene (our elaboration).

The analysis of the perception of the quality of biofortified products was carried out on a sample of 500 consumers. The sample size has been fixed, taking into account the research objectives and available resources, while the units to be interviewed were identified using the method of sampling by quotas; this method is the most common in market surveys because, compared to other methods of probabilistic sampling, it is very flexible $[18,33,44]$.

The survey of 500 consumers was carried out both face to face and using the GoogleDocs platform. Respondents were asked to fill in an ad hoc questionnaire in order to collect a set of quantitative and qualitative information on the socio-economic and cultural demographics of the respondents, as well as on their purchasing behaviour, on their level of knowledge and perception of the quality of biofortified products, and on their willingness to pay on the price of both fresh and processed biofortified tomatoes. 
The questionnaire contained questions with closed or bound answers (binary or multiple), in which the respondent was offered a series of coded options from which the respondent was asked to choose in relation to his position, opinion or mode of behaviour. The questions are of a qualitative type, useful for codifying the opinions expressed by consumers, and of a quantitative type, with numerical answers aimed at identifying the frequencies and methods of consumption, as well as at describing the socio-economic characteristics of the subjects interviewed and their families.

The data collected with the questionnaire were processed according to a methodological scheme commonly used for the study of the characteristics of consumption of certain agri-food products $[19,21,33,45]$. The analysis was divided into two phases with particular attention on the second phase, in order to better understand and explain the typological characteristics of consumers.

In the first phase, the sample as a whole was described, using the tools of univariate statistical analysis, in order to outline the consumers' knowledge of biofortified products.

The next phase concerned the application of multivariate statistical analysis techniques in order to highlight the main variables that influence the consumption of biofortified products and identify homogeneous consumer groups (clusters) [35,46,47].

Initially, the analysis of the "main components" was carried out in order to verify which variables are useful in defining the approach to the consumption of biofortified products. The extraction by "blocks" on each homogeneous group of variables was used, with the Varimax method that allows, through the orthogonalization of the factors, a simpler and more correct interpretation of the factors [48].

The KMO Test was used to verify the statistical model and ascertain the goodness of matching of the hypothesized model to the data [47]; extracted factors with "eigenvalues" greater than 1 have been considered [48].

The main component analysis was followed by the application of cluster analysis to the values assumed by the factors previously extracted, which allowed the identification of homogeneous groups of consumers, using the procedure of non-hierarchical classification of $\mathrm{k}$-medias ( $\mathrm{k}$-means cluster analysis), which allowed us to define, through an iterative process, the clusters minimizing the Euclidean distances assumed by the centroids $[33,35]$.

\section{Results}

In order to establish the main variables that influence the consumption of biofortified products, the analysis of the main components was used, as described above, which allowed us to identify, from the four groups of selected variables, twelve main components that summarize the information about the characteristics of the consumers interviewed.

The first group of variables considered, as documented in Table 1 , are the socio-economic variables and among those surveyed, only eight were able to explain $70.3 \%$ of the total variance, through the extraction of four components (A1; A4).

The first component extracted (A1) alone explains $23.1 \%$ of the variance and describes the characteristics of a part of the sample interviewed, represented by a group of young females, on average married, with clerical employment; in fact, these variables are positively correlated (values $>0$ ) between them and with a diploma level qualification and average annual family income.

The second component (A2), with $19.2 \%$ of the variance explained, is characterized by individuals of medium-high age, married and caring for the family, and responsible for food purchases. In fact, these variables are strongly correlated with each other in a positive way (values $>0$ ).

The third component extracted (A3), with $15.7 \%$ of the total variance explained, shows the middle class of the sample, averagely numerous, characterized above all by males who take care of the family and are not responsible for food purchases.

The fourth component (A4) explains $12.3 \%$ of the variance and highlights and links through positive correlations the professional employees with high levels of education.

The second group of variables, as shown in Table 2, refers to the general characteristics of the consumption of biofortified products. Eleven variables were statistically significant and through the 
application of the analysis of main components we were able to extract four components (B1, B4) that explain $73 \%$ of the total variance.

Table 1. Rotated matrix of components relative to the characteristics of the sample $\left({ }^{*}\right)$.

\begin{tabular}{lcccc}
\hline \multirow{2}{*}{ Variables } & \multicolumn{4}{c}{ Main Components } \\
\cline { 2 - 5 } & $\mathbf{A 1}$ & $\mathbf{A 2}$ & $\mathbf{A 3}$ & $\mathbf{A 4}$ \\
\hline Sex & 0.012 & 0.891 & 0.485 & 0.352 \\
Age class & -0.072 & -0.059 & 0.268 & 0.121 \\
Marital status & 0.274 & 0.158 & 0.157 & 0.241 \\
Qualification & 0.659 & 0.071 & -0.081 & -0.024 \\
Profession & 0.548 & -0.029 & 0.771 & -0.178 \\
Family-run numbering & 0.214 & -0.017 & 0.429 & 0.476 \\
Purchasing Manager & -0.007 & 0.281 & 0.257 & 0.547 \\
Family income & 0.927 & 0.087 & 0.221 & 0.984 \\
\hline Explained variance (\%) & $\mathbf{2 3 . 1}$ & $\mathbf{1 9 . 2}$ & $\mathbf{1 5 . 7}$ & $\mathbf{1 2 . 3}$ \\
\hline
\end{tabular}

$\left({ }^{*}\right)$ Elaboration on directly measured data.

Table 2. Rotated matrix of the components relating to the general characteristics concerning the consumption of biofortified products $\left({ }^{*}\right)$.

\begin{tabular}{lcccc}
\hline \multirow{2}{*}{ Variables } & \multicolumn{4}{c}{ Main Components } \\
\cline { 2 - 5 } & B1 & B2 & B3 & B4 \\
\hline Elements leading to the consumption of biofortified products \\
Food Security & 0.537 & 0.025 & 0.725 & -0.015 \\
Origin & 0.125 & 0.189 & 0.258 & 0.473 \\
Certification & 0.487 & 0.259 & -0.015 & 0.356 \\
Nutritional content & 0.291 & 0.097 & 0.087 & 0.187 \\
Brand & 0.048 & -0.012 & -0.297 & 0.025 \\
Price & 0.361 & 0.644 & 0.125 & 0.282 \\
Frequency of purchase & 0.002 & 0.012 & -0.058 & 0.127 \\
Reasons for consumption & & & & \\
Health & 0.584 & 0.237 & 0.218 & 0.384 \\
Fashion & 0.124 & 0.498 & 0.251 & -0.012 \\
Food Security & 0.247 & 0.359 & 0.267 & 0.194 \\
Willingness to pay & 0.218 & 0.027 & -0.039 & 0.098 \\
\hline Explained variance (\%) & $\mathbf{2 8 . 1}$ & $\mathbf{2 2 . 7}$ & $\mathbf{1 1 . 3}$ & $\mathbf{1 0 . 9}$ \\
\hline
\end{tabular}

$\left(^{*}\right)$ Elaboration on directly measured data.

Specifically, the first component (B1) explains $28.1 \%$ of the variance and summarises the consumption patterns expressed by regular consumers. In this respect, the frequent and high consumption of mainly biofortified fruit and vegetables is due to the higher quality guarantees that these products offer compared to the traditional substitutes. The positive correlations of the variables (values $>0$ ) with television as a source of information highlight the role played by the media in guiding consumer choices (ex. selenium potato).

The second extracted component (B2) explains $22.7 \%$ of the variance and characterizes the form of consumption in which the biofortified product is produced by organic farming techniques and associated with a healthy product.

The third extracted component (B3), which explains $11.3 \%$ of the variance, indicates that the consumption of biofortified products occurs because of the association the consumer makes between health and a certain additive (a microelement or vitamin). 
The fourth component extracted (B4), explains $10.9 \%$ of the variance and identifies the consumption of biofortified products because they are "more nutritious" for the respondent or someone in his or her household.

The third group of variables considered, for the purposes of statistical analysis, refers to the way in which biofortified products are purchased and consumed. The four components extracted from the main component analysis $(\mathrm{C} 1 ; \mathrm{C} 4)$ are able to explain $71.5 \%$ of the variance. The values of the factorial scores related to the information "synthesized" by the eight variables that were better able to explain the phenomenon investigated, are documented in Table 3.

Table 3. Rotated component matrix of characteristics related to the purchase and consumption of biofortified products $\left({ }^{*}\right)$.

\begin{tabular}{lcccc}
\hline \multicolumn{1}{c}{ Variables } & \multicolumn{4}{c}{ Main Components } \\
\cline { 2 - 5 } & $\mathbf{C 1}$ & $\mathrm{C} 2$ & $\mathrm{C} 3$ & C4 \\
\hline $\begin{array}{l}\text { Places of purchase } \\
\text { Supermarket }\end{array}$ & 0.523 & 0.429 & 0.551 & 0.369 \\
$\begin{array}{l}\text { Traditional market and } \\
\text { farmer's market }\end{array}$ & 0.268 & 0.219 & -0.112 & -0.028 \\
$\begin{array}{l}\text { Main obstacles to purchase } \\
\text { Difficulty finding }\end{array}$ & 0.877 & 0.915 & 0.743 & 0.985 \\
$\begin{array}{l}\text { High prices } \\
\text { Non-differentiation }\end{array}$ & 0.365 & 0.712 & -0.118 & -0.028 \\
$\begin{array}{l}\text { Appreciated factors for biofortified } \\
\text { products }\end{array}$ & 0.539 & 0.597 & 0.391 & 0.984 \\
$\begin{array}{l}\text { Medical-scientific recognition } \\
\text { Standards }\end{array}$ & 0.361 & 0.096 & 0.239 & -0.009 \\
Certification & 0.671 & 0.594 & 0.784 & 0.127 \\
\hline Explained variance (\%) & 0.234 & -0.019 & 0.235 & 0.231 \\
\hline
\end{tabular}

$(*)$ Elaboration on directly measured data.

The first component extracted (C1), which alone accounts for $23.4 \%$ of the variance, concerns awareness of the importance of product certification. The component is also characterized by the preference of the supermarket as the place of purchase, where the consumer allocates significant percentages of their income for the purchase of food products. Finally, there is the perception of the higher cost that distinguishes these products compared to substitutes.

The second component (C2), which explains $21.7 \%$ of the variance, is characterized by the fact that the main obstacle encountered in the purchase of biofortified products is the difficulty in finding them, therefore the consumer allocates a very limited portion of his or her annual income to their purchase, while accepting the higher price for these products.

The third component (C3), with $14.1 \%$ of the total variance, highlights that the poorly-differentiated quality of biofortified products is the main obstacle encountered by consumers in purchasing such products.

The fourth component (C4), which explains $12.3 \%$ of the total variance, is characterized by the preference of farmers' markets as a place of purchase, where the higher cost is accepted because of the value of the direct contact with the producer.

\subsection{Consumers Clusters}

The cluster analysis of twelve components extracted and identified by the main component analysis identified four homogeneous groups of consumers of biofortified products. The characterization of these groups is well summarized in Table 4 , in which the factorial scores in the centroids of the groups obtained by the application of the K-medias method are reported. 
Table 4. Value of the final cluster centres $\left.{ }^{*}\right)$.

\begin{tabular}{ccccc}
\hline \multirow{2}{*}{ Main Components } & \multicolumn{4}{c}{ Consumer Groups } \\
\cline { 2 - 5 } & $\mathbf{1}$ & $\mathbf{2}$ & $\mathbf{3}$ & $\mathbf{4}$ \\
\hline A1 & 0.269 & 0.012 & -0.039 & 0.313 \\
A2 & 0.639 & -0.237 & 0.129 & -0.041 \\
A3 & -0.018 & 0.219 & 0.014 & -0.021 \\
A4 & 0.737 & 0.087 & 0.277 & 0.029 \\
B1 & 0.527 & -0.121 & 0.039 & -0.327 \\
B2 & -0.069 & 0.019 & 0.039 & 0.287 \\
B3 & 0.367 & 0.211 & 0.011 & 0.261 \\
B4 & 0.291 & -0.197 & 0.063 & -0.009 \\
C1 & 0.169 & 0.123 & -0.274 & -0.028 \\
C2 & 0.537 & 0.021 & 0.127 & 0.023 \\
C3 & 0.491 & 0.297 & -0.251 & 0.124 \\
C4 & 0.293 & 0.052 & 0.077 & 0.103 \\
\hline Sample size (\%) & 37.2 & $\mathbf{2 3 . 3}$ & $\mathbf{2 2 . 7}$ & $\mathbf{1 6 . 8}$ \\
\hline
\end{tabular}

$\left(^{*}\right)$ Elaboration on directly measured data.

\subsubsection{Group 1-Uninformed Consumers}

The first group of consumers, representing $37.2 \%$ of the sample, is characterised by young men, with an average level of education, and with a low-middle income level. With regard to consumption characteristics, the group prefers biofortified products they have come to know through the media and consume these in very low percentages compared to traditional substitute products. For these products, one is not willing to pay a premium price for their consumption. Large retailers are the places where they are familiar with seeing these products, even if they are not willing to buy them. The main obstacle that this group of consumers encounters when buying biofortified products is the quality of the product, which is so undifferentiated that the consumer can allocate only part of its family expenditure.

\subsubsection{Group 2-Aware Consumers}

The second group of consumers, equal to $23.3 \%$ of the sample, stands out from the other groups from a socio-economic point of view because it is characterized mainly by women who take care of the family in all respects. They are the people responsible for purchasing, and belong to a family unit composed of a few members and with a high level of income.

This group of consumers tends to consume biofortified products "by trend" as they are considered "more nutritious" and "healthy"; for this reason the product consumed is a substitute for traditional products, a theory supported by the fact that we tend to prefer the supermarket as a place of purchase where we have the perception that on average premium products cost no more than $10-20 \%$ more than traditional products.

\subsubsection{Group 3-Health-Conscious Consumers}

The third group of consumers accounts for $22.7 \%$ of the total sample and is mainly made up of young women, unmarried and with a high level of education. They consume biofortified products sporadically, even if they are not able to identify the elements that characterize these products. In fact, the small percentage of fruit and vegetables consumed, while recognizing a differentiated quality of merchandise, occurs more out of habit than for other health reasons, indicating a targeted consumption. The place of purchase is both the supermarket and the farmers' market, where they find a limited assortment, and therefore consumption is low. 


\subsubsection{Group 4-Non-Health-Conscious Consumers}

Finally, the fourth group is characterized by a high number of family members with a low-medium income profile and an average level of education, which made up $16.8 \%$ of the sample. Even though this group's consumption is conditioned by advertising, they are not inclined to buy biofortified products as they are not willing to pay more than substitute products.

The cluster analysis has made it possible to highlight the presence of four emerging consumption profiles. The most common group is characterized by specific dynamics within a group of uninformed and unaware consumers with a limited propensity to buy. This is followed by the group concerned about health and products, who maintain and improve their health and have a good propensity to buy. Next, we have the group of aware consumers who sporadically buy biofortified products but do point out a limited willingness to pay, and finally consumers not attentive to health who are not willing to buy biofortified products except out of curiosity and only if they do not cost more than the products' substitutes.

\section{Conclusions}

The analysis carried out allowed us to define the current profile of the consumer of biofortified products in Italy. Overall, the research presents an interesting starting point for discussion that shows an empirical framework that is complex, but at the same time very clear, with reference to some of the main dynamics that govern the demand for biofortified products [49]. The informed consumer of biofortified products is extremely determined to purchase them and is willing to pay high prices. In Italy today, however, aware and informed consumers are a very limited segment of the market. Research has placed particular emphasis on the role of market information [38], allowing us to understand how the different information assets available to consumers are reflected in the purchase and consumption choices of biofortified foods. It has therefore been possible to highlight, through the interpretation of emerging consumption profiles, that there is: a targeted purchase by those who, concerned about their health, are looking for foods that can preserve or improve it; a conscious purchase by people who firmly believe in the benefits brought by functional foods but only sporadically integrate them into their diet; as well as a completely occasional purchase resulting from the curiosity aroused by advertising. Probably, as often happens in most cases, all mean the same thing [1]. The analysis shows the presence of consumers completely uninformed and unaware of the availability of such products, and therefore not interested in purchasing them.

These results suggest the main role that campaigns to communicate health-related properties could play in influencing market dynamics. The scientific research results on the benefits on human health have an impact on the demand for new products, even more so if they are food credentials, with long-term nutritional and functional characteristics that are difficult to verify in terms of effectiveness [3].

The problem of information of the biofortified products is related to the credibility of claims and the presence of information asymmetry. As the analysis shows, consumers also make their purchasing decisions on the basis of information on labels or communicated in advertising campaigns.

It is clear from the research that the Italian consumer is not willing to consume genetically modified products (GMOs), as they consider them unhealthy and are totally in contrast to their idea of biofortified products. This assumption is confirmed because biofortified products for many consumers should be organic, as they are safe and have a positive effect on health.

This research has therefore identified a consumer who has a growing interest in biofortified products and their health content, but is totally unrelated to the profile of consumers of biofortified products in other areas of the world, where consumption is determined by the need to supply micro-nutrients regardless of the method used to produce them.

This scenario of biofortified products, however, is the general situation that can also be observed at the CODEX level with many countries referring to individual continents (Africa, Asia) that are moving 
towards the production of biofortified products through GMOs. Western countries, on the other hand, are increasingly oriented towards the production of biofortified products through agronomic techniques.

Author Contributions: G.T. and A.S.: Both of them did the conceptualization the idea of study design, A.S. and G.T.: writeup of the methodology. V.T.F. and C.B.: Both did the review, editing, formal data analysis, and validation C.B.: undertook the survey, review and editing. All authors have read and agreed to the published version of the manuscript.

Funding: The research leading to these results has received funding from:

(1) research project "Valutazione della sostenibilità dei sistemi agroalimentari locali” WP4, coordinated by Prof. Iuri Peri financially supported by the University of Catania;

(2) research project "Sostenibilità economica, ambientale e sociale del sistema agroalimentare del mediterraneo", Principal investigator Prof. Claudio Bellia funded by PIAno di inCEntivi per la Ricerca di Ateneo (PIACERI) UNICT 2020/22 line 2, University of Catania.

Conflicts of Interest: The authors declare no conflict of interest.

\section{References}

1. Bech-Larsen, T.; Grunert, K.G. The perceived healthiness of functional foods: A conjoint study of Danish, Finnish and American consumers' perception of functional. Appetite 2003, 40, 9-14. [CrossRef]

2. Beer, H.; Luna, S.; Popmpano, L.; Przybyszewski, E.; Udipi, S.; Ghugre, P.; Haas, J. Consuming iron-biofortified pearl millet increased hemoglobin concentrations and prevented a decline in energy efficiency in Indian girls. J. Fed. Am. Soc. Exp. Biol. 2014, 28, 646-647.

3. Birol, E.; Meenakshi, J.V.; Oparinde, A.; Perez, S.; Tomlins, K. Developing country consumers' acceptance of biofortified foods: A synthesis, 2015. Food Secur. 2015, 7, 555-568. [CrossRef]

4. Diplock, A.T.; Aggett, P.J.; Ashwell, M.; Bornetm, F.; Fern, E.B.; Roberfroid, M.B. Scientific concepts of functional foods in Europe: Consensus document. Br. J. Nutr. 1999, 81, S1-S27.

5. Weststrate, J.A.; van Poppel, G.; Verschuren, P.M. Functional foods, trends and future. Br. J. Nutr. 2002, 88 (Suppl. 2), 233-235. [CrossRef]

6. Bryce, J.; El Arifeen, S.; Pariyo, G.; Lanata, C.F.; Gwatkin, D.; Habicht, J. Multi-country valuation of IMCI Study Group. Reducing child mortality: Can public health deliver? Lancet 2003, 362, 159-164.

7. Menrad, K. Market and marketing of functional food in Europe. J. Food Eng. 2003, 56, 181-188. [CrossRef]

8. Scuderi, A.; Sturiale, L.; Timpanaro, G. Economic evaluation of innovative investments in agri-food chain. Qual. Access Success 2018, 19, 482-488.

9. Verbeke, W. Consumer acceptance of functional foods: Socio-demographic, cognitive and attitudinal determinants. Food Qual. Prefer. 2005, 16, 45-57. [CrossRef]

10. Annunziata, A.; Misso, R. Alimentazione, salute e benessere del consumatore: Da determinanti di scelta a opportunità di mercato. Riv. Econ. Agro-Aliment. 2010, 1, 119-135.

11. Bouis, H.E.; Eozenou, P.; Rahman, A. Food prices, household income, and resource allocation: Socioeconomic perspectives on their effects on dietary quality and nutritional status. Food Nutr. Bull. 2011, 32, S14-S23. [CrossRef] [PubMed]

12. Canavari, M.; Castellini, A.; Pirazzoli, C. Functional Foods in European Union. An Overview of the Sector's Main Issue. Centre for International Food and Agricultural Policy; University of Minnesota: Red Cedar Lake, WI, USA.

13. Ashwell, M. Concepts of Functional Foods; International Life Sciences Institute ILSI: Brussels, Belgium, 2002.

14. Naico, A.T.A.; Lusk, J.L. The value of a nutritionally enhanced staple crop: Results from a choice experiment conducted with orange fleshed sweet potatoes in Mozambique. J. Afr. Econ. 2010, 19, 536-558. [CrossRef]

15. De Brauw, A.; Eozenou, P.; Gilligan, D.; Kumar, N.; Meenakshi, J. Biofortication, crop adoption and health information: Impact pathways in Mozambique and Uganda. Am. J. Agric. Econ. 2018, 100, 906-930. [CrossRef] [PubMed]

16. Del Giudice, T.; Nebbia, S.; Pascucci, S. The role of consumer acceptance in the food innovation process: Young consumer perception of functional food in Italy. In Proceedings of the2009 International European Forum, Innsbruck-Igls, Austria, 15-20 February 2009. [CrossRef]

17. Gonzalez, C.; Johnson, N.; Qaim, M. Consumer acceptance of second-generation gm foods: The case of biofortified cassava in the north-east of brazil. J. Agric. Econ. 2009, 60, 604-624. [CrossRef] 
18. Alfnes, F.; Rickertsen, K. European consumers' willingness to pay for U.S. beef in experimental auction markets. Am. J. Agric. Econ. 2003, 85, 396-405. [CrossRef]

19. Barreiro-Hurlé, J.; Colombo, S.; Cantos-Villar, E. Is there a market for functional wine? Consumer preferences and willingness to pay for resveratrol-enriched red wine. Food Qual. Prefer. 2008, 19, 360-371. [CrossRef]

20. Defrancesco, E.; Galvan, A. Functional foods: Consumers' willingness to pay for red chicory "Radicchio di Chioggia" enhanced with antioxidant compounds. In Food, Agriculture and the Environment; Defrancesco, E., Galletto, L., Thiene, M., Franco, A., Eds.; Franco Angeli: Milano, Italy, 2005; pp. 259-274.

21. Saltzman, A.; Birol, E.; Bouis, H.; Boy, E.; Moura, F.; Islam, Y.; Pfeiffer, W. Biofortification: Progress toward a more nourishing future. Glob. Food Secur. 2013, 2, 9-17. [CrossRef]

22. Cannella, C.; Giusti, A.M.; Pinto, A. Dal Cibo per Tutti Agli Alimenti Personalizzati (From Food to All to Personalised Foodstuffs); Pensiero Scientifico Editore: Rome, Italy, 2007.

23. Chowdhury, S.; Meenakshi, J.V.; Tomlins, K.; Owori, C. Are consumers in developing countries willing to pay more for micronutrient dense biofortified foods? Evidence from a field experiment in Uganda. Am. J. Agric. Econ. 2011, 93, 83-97. [CrossRef]

24. Codex Alimentarius Commission. Proposed Draft Definition for Biofortification, CX/NFSDU 18/40/7, 26-30 November 2018 Berlin, Germany. 2018. Available online: https:/ec.europa.eu/food/safety/international_ affairs/standard_setting_bodies/codex/ccnfsdu_en, (accessed on 5 February 2020).

25. Codex Alimentarius Commission. Proposed Draft Definition for Biofortification, CX/NFSDU 17/39/5, 04-08 December 2017 Berlin, Germany. 2017. Available online: https://ec.europa.eu/food/safety/international_ affairs/standard_setting_bodies/codex/ccnfsdu_en (accessed on 5 February 2020).

26. Haas, J.; Finkelstein, J.; Udipi, S.; Ghugre, P.; Mehta, S. Iron biofortified pearl millet improves iron status in Indian school children: Results of a feeding trial. J. Fed. Am. Soc. Exp. Biol. 2013, 27, 355.2.

27. Nestel, P.; Bouis, H.E.; Meenakshi, J.; Pfeiffer, W. Biofortification of staple foodcrops. J. Nutr. 2006, 136, 1064-1067. [CrossRef]

28. Bellia, C.; Pilato, M. Actuality and future prospects on GMO crops in agriculture: Some main aspects and problems. Qual. Access Success 2011, 12, 280-288.

29. Oparinde, A.; Birol, E.; Murekezi, A.; Katsvairo, L.; Tedla Diressie, M.; Nkundimana, J.D.; Butare, L. Consumer Acceptance of Biofortified Iron Beans in Rural Rwanda: Experimental Evidence; International Food Policy Research Institute (IFPRI): Washington, DC, USA, 2015.

30. World Health Organization (WHO). Vitamin and Mineral Nutrition Information System (VMNIS). 2020. Available online: https://www.who.int/vmnis/en/ (accessed on 2 February 2020).

31. Bondoc, I. European Regulation in the Veterinary Sanitary and Food Safety Area, a Component of the European Policies on the Safety of Food Products and the Protection of Consumer Interests: A 2007 Retrospective. Part One: The Role of European Institutions in Laying Down and Passing Laws Specific to the Veterinary Sanitary and Food Safety Area. Available online: http://revista.universuljuridic.ro/supliment/european-regulation-veterinary-sanitary-food-safety-areacomponent-european-policies-safety-food-products-protection-consumer-interests-2007-retrospective/ (accessed on 20 July 2020).

32. Basmann, R.L. A theory of demand with variable consumer preferences. Econometrica 1956, 24, 47-58. [CrossRef]

33. Chinnici, G.; Pecorino, B.; Scuderi, A. La percezione della qualità dei prodotti tipici da parte del consumatore in Sicilia. Econ. Agroaliment. 2012, 1, 143-172.

34. Scuderi, A.; Bellia, C.; Foti, V.T.; Sturiale, L.; Timpanaro, G. Evaluation of consumers' purchasing process for organic food products. AIMS Agric. Food 2019, 4, 251-265. [CrossRef]

35. Hu, W.; Woods, T.; Bastin, S. Consumer cluster analysis and demand for blueberry jam attributes. J. Food Prod. Mark. 2009, 15, 420-435. [CrossRef]

36. Timpanaro, G.; Foti, V.T.; Scuderi, A.; Branca, F.; Schippa, G. New food supply chain systems based on a proximity model: The case of an alternative food network in the Catania urban area. Acta Hortic. 2018, 1215, 213-217. [CrossRef]

37. De Groote, H.; Kimenju, S.C.; Morawetz, U.B. Estimating consumer willingness to pay for food quality with experimental auctions: The case of yellow versus fortified maize meal in Kenya. Agric. Econ. 2011, 42, 1-16. [CrossRef] 
38. Akerlof, G.A. The market for 'lemons': Quality uncertainty and the market mechanism, quarterly. J. Econ. 1970, 84, 488-500. [CrossRef]

39. Muzinghi, T.; Langyintuo, A.S.; Malaba, L.C.; Banziger, M. Consumer acceptability of yellow maize products in Zimbabwe. Food Policy 2008, 33, 352-361. [CrossRef]

40. Bondoc, I. European Regulation in the Veterinary Sanitary and Food Safety Area, a Component of the European Policies on the Safety of Food Products and the Protection of Consumer Interests: A 2007 Retrospective. Part Two: Regulations. Available online: http://revista.universuljuridic.ro/supliment/european-regulationveterinary-sanitary-food-safety-area-component-european-policies-safety-food-products-protectionconsumer-interests-2007-retrospective-2/ (accessed on 20 July 2020).

41. Bondoc, I. European Regulation in the Veterinary Sanitary and Food Safety Area, a Component of the European Policies on the Safety of Food Products and the Protection of Consumer Interests: A 2007 Retrospective. Part Three: Directives. Available online: http://revista.universuljuridic.ro/supliment/ european-regulation-veterinary-sanitary-food-safety-area-component-european-policies-safety-foodproducts-protection-consumer-interests-2007-retrospective-part/ (accessed on 20 July 2020).

42. Bondoc, I. European Regulation in the Veterinary Sanitary and Food Safety Area, a Component of the European Policies on the Safety of Food Products and the Protection of Consumer Interests: A 2007 Retrospective. Part Four: Decisions. Available online: http://revista.universuljuridic.ro/supliment/europeanregulation-veterinary-sanitary-food-safety-area-component-european-policies-safety-food-productsprotection-consumer-interests-2007-retrospective-part-2/ (accessed on 20 July 2020).

43. Garcia Montecinos, K.L.; Godoy, J.A.; Carrillo Centeno, P.; Pachón, H. Evaluación sensorial de arroz (Oryza sativa) variedad Azucena en la Región Autónoma del Atlántico Norte en Nicaragua. Perspect. En Nutr. Hum. 2011, 13, 135-146.

44. Wooldridge, J.M. Econometric Analysis of Cross Section and Panel Data; MIT Press: Cambridge, MA, USA, 2001.

45. Harrison, G.W.; Harstad, R.; Ruström, E. Experimental methods and elicitation of values. Exp. Econ. 2004, 7, 123-140. [CrossRef]

46. Hair, J.F.; Anderson, R.E.; Tatham, R.L.; Black, W.C. Analisis Multivariante, 5th ed.; Pearson Prentice Hall: Madrid, Spain, 2007.

47. Kaiser, H.F. The application of electronic computers to factor analysis. Educ. Psychol. Meas. 1960, 20, $141-151$. [CrossRef]

48. Kaiser, H.F. The Varimax criterion for analytic rotation in factor analysis. Psychometrika 1958, 23, $187-200$. [CrossRef]

49. De Steur, H.; Gellynck, X.; Blancquaert, D.; Lambert, W.; Van Der Straeten, D.; Qaim, M. Potential impact and cost effectiveness of multi-biofortified rice in China. New Biotechnol. 2012, 29, 432-442. [CrossRef] 